\title{
Does blood urea nitrogen level predict severity and high-risk endoscopic lesions in patients with nonvariceal upper gastrointestinal bleeding?
}

\author{
Khalid Al-Naamani MD ${ }^{1}$, Nabil Alzadjali MD², Alan N Barkun MD MSc (Epidemiology) ${ }^{1,3}$, Carlo A Fallone MD ${ }^{1}$
}

K Al-Naamani, N Alzadjali, AN Barkun, CA Fallone. Does blood urea nitrogen level predict severity and high-risk endoscopic lesions in patients with nonvariceal upper gastrointestinal bleeding? Can J Gastroenterol 2008;22(4):399-403.

BACKGROUND: Nonvariceal upper gastrointestinal bleeding (UGIB) is a serious medical condition requiring prompt resuscitation and early endoscopic therapy in those with high-risk endoscopic lesions (HRLs). There are little or no data correlating sole blood urea nitrogen (BUN) level with the severity of nonvariceal UGIB or the presence of HRLs in the adult population.

OBJECTIVES: To determine if the BUN level on presentation correlates with parameters of severity of UGIB (need for blood transfusion or intensive care unit [ICU] admission) or to the subsequent finding of HRL, and in so doing identify patients who will require early endoscopic intervention.

METHODS: The Canadian Registry of patients with Upper Gastrointestinal Bleeding undergoing Endoscopy was used to identify patients enrolled from the McGill University Health Centre (Montreal, Quebec) who presented with or developed acute nonvariceal UGIB while admitted. All comparisons were performed using Student's $t$ test or Wilcoxon's signed rank test, as appropriate. Logistic regression modelling using a stepwise method was performed to identify independent predictors of severe nonvariceal UGIB and HRL. RESULTS: Two hundred nine patients were enrolled in the study. The mean age was $67 \pm 18$ years and $59.8 \%$ were male. The mean BUN level was $13.4 \pm 9.4 \mathrm{mmol} / \mathrm{L}$. Univariate analysis demonstrated that the BUN level was a significant predictor of ICU admission (BUN $14.7 \pm 10.4 \mathrm{mmol} / \mathrm{L}$ versus $12.0 \pm 8.0 \mathrm{mmol} / \mathrm{L}, \mathrm{P}=0.035)$. However, when adjusted for systolic blood pressure, BUN level became a weaker predictor of ICU admission, just failing to achieve statistical significance (OR 1.03, 95\% CI 1.00 to $1.06 ; \mathrm{P}=0.08$ ). Univariate analysis also demonstrated that BUN level was not a statistically significant predictor of blood transfusion requirement (BUN $14.1 \pm 10.6 \mathrm{mmol} / \mathrm{L}$ versus $13.6 \pm 8.6 \mathrm{mmol} / \mathrm{L}, \mathrm{P}=0.508$ ), nor of HRL (BUN $14.2 \pm 10.7 \mathrm{mmol} / \mathrm{L}$ versus $12.9 \pm 8.6 \mathrm{mmol} / \mathrm{L}, \mathrm{P}=0.605)$.

CONCLUSION: In patients with nonvariceal UGIB, the BUN level at initial presentation is a weak predictor of the severity of UGIB as defined by ICU admission, but is not helpful in identifying patients with a HRL.

Key Words: BUN; High-risk lesions (endoscopic); Predictors; Upper gastrointestinal bleed

$A$ cute nonvariceal upper gastrointestinal bleeding (UGIB)

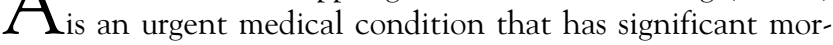
bidity, mortality and health care resource use (1).

The estimated annual incidence of acute UGIB is between 100 and 200 per 100,000 population (2,3). More than $50 \%$ of these cases are due to peptic ulcer disease (4-8). Patients who
Le taux d'azote uréique du sang permet-il de prédire la gravité et le risque élevé des lésions à l'endoscopie chez des patients en hémorragie digestive haute non variqueuse?

HISTORIQUE : L'hémorragie digestive haute (HDH) non variqueuse est une maladie grave qui requiert une réanimation rapide et un traitement endoscopique précoce chez les sujets atteints de lésions endoscopiques à risque élevé (LERÉ). Les données corrélant le taux d'azote uréique du sang (AUS) seul à la gravité de l'HDH non variqueuse ou à la présence de LERÉ sont peu nombreuses, voire inexistantes chez la population adulte.

OBJECTIFS : Déterminer si le taux d'AUS au moment de la consultation est en corrélation avec les paramètres de gravité de l'HDH (dépendance transfusionnelle ou hospitalisation à l'unité des soins intensifs [USI]) ou avec la découverte subséquente des LERÉ permettant d'identifier des patients susceptibles de nécessiter une intervention endoscopique rapide.

MÉTHODES : Les auteurs ont consulté le Registre canadien des patients atteints d'hémorragie digestive haute devant subir une endoscopie pour recenser les patients inscrits au Centre universitaire de santé McGill (Montréal, Québec) qui présentaient ou développaient une HDH aiguë au moment de leur admission. Toutes les comparaisons ont été réalisées à l'aide du test $t$ de Student ou du test de Wilcoxon, selon le cas. Les différentes étapes du modèle de régression logistique ont été appliquées à l'identification des prédicteurs indépendants de l'HDH non variqueuse et des LERÉ graves.

RÉSULTATS : Deux-cent-neuf patients ont été inscrits à l'étude, l'âge moyen était de $67 \pm 18$ ans et 59,8\% étaient de sexe masculin. Le taux moyen d'AUS était de 13,4 $\pm 9,4 \mathrm{mmol} / \mathrm{L}$. L'analyse univariée a montré que le taux d'AUS était un prédicteur important de l'admission à l'unité des soins intensifs (USI) (AUS 14,7 $\pm 10,4 \mathrm{mmol} / \mathrm{L}$, contre 12,0 \pm $8,0 \mathrm{mmol} / \mathrm{L}, \mathrm{p}=0,035)$. Par contre, après ajustement pour tenir compte de la tension artérielle systolique, le taux d'AUS est devenu un prédicteur plus faible de l'hospitalisation à l'USI, à la limite de la portée statistique (RR 1,03, IC à $95 \%, 1,00$ à 1,06; p = 0,08). L'analyse univariée a aussi montré que le taux d'AUS n'était pas un prédicteur statistiquement significatif de la dépendance transfusionnelle (AUS 14,1 $\pm 10,6 \mathrm{mmol} / \mathrm{L}$, contre 13,6 $\pm 8,6 \mathrm{mmol} / \mathrm{L}, \mathrm{p}=0,508$ ) ni des LERÉ (AUS 14,2 $\pm 10,7 \mathrm{mmol} / \mathrm{L}$, contre $12,9 \pm 8,6 \mathrm{mmol} / \mathrm{L}, \mathrm{p}=0,605)$.

CONCLUSION : Chez les patients qui présentent une HDH non variqueuse, le taux d'AUS au moment de la consultation est un faible prédicteur de la gravité de l'HDH définie par l'admission à l'USI, mais n'est pas utile au dépistage des LERÉ chez les patients atteints.

have a history of acute UGIB present with a wide range of clinical severity, from insignificant bleeds to catastrophic exsanguinations.

Clinical findings such as low blood pressure, postural hypotension and tachycardia can help primary and specialty physicians to differentiate severe from nonsevere UGIB.

${ }^{1}$ Division of Gastroenterology; ${ }^{2}$ Division of Emergency; ${ }^{3}$ Division of Clinical Epidemiology, McGill University Health Centre, Montreal, Quebec Correspondence: Dr Carlo A Fallone, Division of Gastroenterology, Royal Victoria Hospital - Ross 228, 687 Pine Avenue West, Montreal,

Quebec H3A 1A1. Telephone 514-843-1616, fax 514-843-1421, e-mail carlo.fallone@muhc.mcgill.ca

Received for publication October 4, 2007. Accepted February 5, 2008. 
TABLE 1

\section{Study population demographics}

\begin{tabular}{lcc}
\hline Characteristic & $\mathbf{n}(\mathbf{\%}), \mathbf{n = 2 0 9}$ & $\mathbf{9 5 \%} \mathbf{C l}^{*}$ \\
\hline Age, mean \pm SD, years & $67 \pm 18$ & \\
Sex & & \\
$\quad$ Male & $125(59.8)$ & $53.1-66.5$ \\
$\quad$ Female & $84(40.2)$ & $33.5-47.2$ \\
BUN, mean \pm SD, mmol/L & $13.4 \pm 9.4$ & \\
ICU admission & $111(53.1)$ & $46.3-60.0$ \\
Blood transfusion & $98(45.1)$ & $46.8-61.5$ \\
ICU admission and blood transfusion & $67(32.1)$ & $25.7-38.4$ \\
Neither ICU admission nor & $45(21.5)$ & $15.9-27.2$ \\
$\quad$ blood transfusion & & \\
Endoscopic high-risk lesion & $78(37.3)$ & $30.7-43.9$ \\
\hline
\end{tabular}

${ }^{*} 95 \% \mathrm{Cls}$ are reported for the percentage of patients for each characteristic. BUN Blood urea nitrogen; ICU Intensive care unit

However, these clinical findings are not always reliable, especially in elderly populations with multiple comorbidities and who take many medications that may alter vital signs. In addition, the initial hemoglobin level and, in particular, the hematocrit level may not reflect a patient's true blood level, because they may be falsely elevated as a result of hemoconcentration $(9,10)$ or may be affected by a chronic anemic state in addition to the acute bleeding event.

Many scoring systems have been established to help clinicians manage patients with UGIB (11). One of these scoring systems, the Blatchford scale, uses blood urea nitrogen (BUN) as one of the variables to prognosticate the outcome of a patient with UGIB. However, the study population used by Blatchford et al (12) included both patients with variceal and those with nonvariceal UGIB. High BUN is mentioned in many medical textbooks as a sign of UGIB, either because of ingested blood proteins or prerenal azotemia (13).

Recently, a few studies have suggested a role for the BUN to creatinine ratio in localizing the site of gastrointestinal bleeding (14-16). Ernst et al (15) showed that the BUN to creatinine ratio correlates significantly with UGIB; a ratio higher than 36 exhibited a sensitivity of $90 \%$, but a specificity of only $27 \%$. Chalasani et al (16) concluded that this ratio is not specific due to a high degree of overlap between UGIB and lower gastrointestinal bleeding, especially in patients without hematemesis. Therefore, this ratio may simply reflect intravascular volume depletion and resultant prerenal azotemia. The same authors also found that the degree of elevation in the BUN to creatinine ratio correlates best with transfusion requirements rather than admission vital signs.

Endoscopic findings, in their own right, also guide the decision of whether to admit a patient, and if so, the need for an intensive care unit (ICU) admission. High-risk endoscopic lesions (HRLs), defined as the presence of active bleeding (spurting or oozing), a nonbleeding visible vessel or an adherent clot are associated with an increased risk for persistent and recurrent UGIB. Laine and Peterson (17) reported that the rate of further bleeding was less than $5 \%$ in patients with a clean ulcer base and increased to $10 \%$ in patients with a flat spot, $22 \%$ in those with an adherent clot, $43 \%$ in those with a nonbleeding visible vessel and 55\% in those with active bleeding (oozing and spurting). Patients with HRLs benefit from early endoscopy within the first $24 \mathrm{~h}$, as well as aggressive endoscopic
TABLE 2

Study population - potential covariates

\begin{tabular}{lcc}
\hline Characteristic & $\mathbf{n}(\%), \mathbf{n = 2 0 9}$ & $\mathbf{9 5 \%} \mathbf{C l}^{*}$ \\
\hline $\begin{array}{l}\text { Systolic blood pressure }(<90 \mathrm{mmHg}) \\
\text { ASA score }^{\dagger}\end{array}$ & $190(90.9)$ & $87.0-94.8$ \\
$1-2$ & $65(31)$ & $24.8-37.4$ \\
3 & $93(44)$ & $37.7-51.3$ \\
$4-5$ & $51(24)$ & $18.5-30.3$ \\
Rectal examination & & \\
Bright red blood per rectum & $18(9)$ & $4.8-12.6$ \\
Melena & $98(47)$ & $40.5-54.2$ \\
Occult blood-positive & $59(28)$ & $22.3-34.7$ \\
Occult blood-negative & $18(9)$ & $4.8-12.6$ \\
$\quad$ Not documented & $16(8)$ & $4.0-11.3$ \\
Nasogastric aspirate yield & & \\
Bright red blood & $45(22)$ & $15.7-27.4$ \\
Coffee grounds & $52(25)$ & $19.0-30.8$ \\
Bile & $10(5)$ & $1.5-7.1$ \\
Tube not placed or not documented & $102(49)$ & $42.0-55.6$ \\
\hline
\end{tabular}

*95\% Cls are reported for the percentage of patients for each characteristic ${ }^{\dagger}$ American Society of Anesthesiologists (ASA) classification of a patient's severity and acuity of disease

hemostatic therapy, because this intervention has been shown to improve patient outcomes, including mortality (18).

The objectives of the present study were to first determine whether the BUN level on presentation correlates with parameters of severity of nonvariceal UGIB, identified by the need for ICU admission and blood transfusions, and second, to assess the ability of the initial BUN level to predict a subsequent finding of HRL, thus facilitating early risk stratification of patients and the need for early endoscopy.

\section{METHODS}

The Canadian Registry on nonvariceal Upper Gastrointestinal Bleeding and Endoscopy (RUGBE) (8) was used to identify patients enrolled from the McGill University Health Centre (MUHC) in Montreal, Quebec who presented with or developed acute nonvariceal UGIB while admitted. Previous publications detail the methods with regard to selection criteria and data validation of this registery $(8,19)$.

Data were collected from the RUGBE database; patient charts were also retrieved and reviewed to collect data more specific to the present study that were not available in the RUGBE database. The registry was approved by the institutional ethics review board.

The following variables were assessed: age, sex, comorbidities, symptoms and signs of gastrointestinal bleeding, the American Society of Anesthesiologists score, vital signs, nasogastric aspiration findings, hemoglobin, serum BUN and creatinine levels, the need for blood transfusion, ICU admission and endoscopic findings (Tables 1 and 2). Patients with known renal failure (creatinine level greater than $120 \mu \mathrm{mol} / \mathrm{L}$ for the last three months or on dialysis), liver cirrhosis and pregnancy, and patients with predefined confounding conditions that may alter the BUN level (ie, fever, trauma, infection, on steroids) were excluded. Patients with no initial serum BUN or creatinine levels available were also excluded.

Severe UGIB was defined as the need for blood transfusion within $24 \mathrm{~h}$ of presentation to the emergency room or the need 


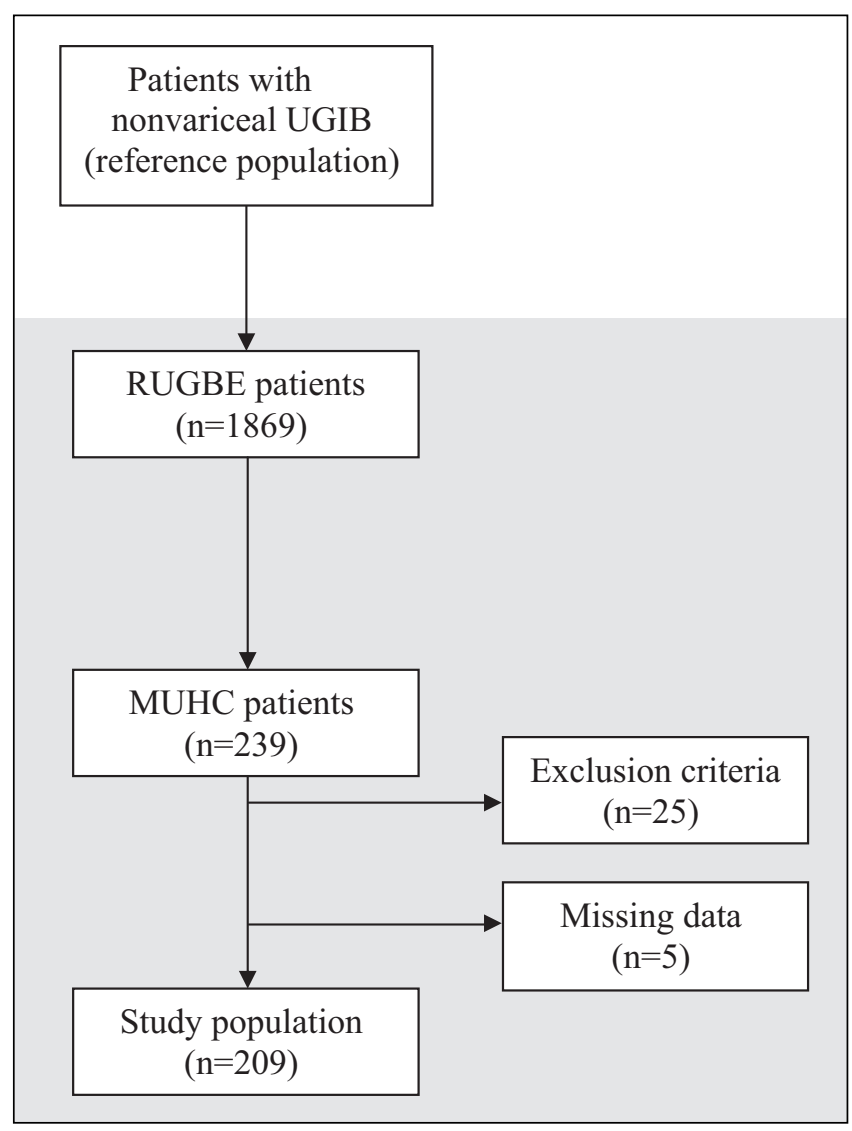

Figure 1) Flow diagram for the selection of patients for the study population. MUHC McGill University Health Centre (Montreal, Quebec); RUGBE Registry on nonvariceal Upper Gastrointestinal Bleeding and Endoscopy; UGIB Upper gastrointestinal bleeding

for ICU admission because of UGIB. According to an established critical path in place at the MUHC at the time of delivery of care, a blood transfusion at the MUHC is considered for patients with a hemoglobin level lower than $70 \mathrm{~g} / \mathrm{L}$ or a drop in hemoglobin level by $20 \mathrm{~g} / \mathrm{L}$ or greater that is not due to fluid resuscitation. Preset indications for ICU admissions due to an episode of UGIB included hypotension (systolic blood pressure [SBP] lower than $90 \mathrm{mmHg}$ ) refractory to fluid resuscitation in the emergency room or findings of HRLs (active bleeding, spurting or oozing, nonbleeding visible vessel or adherent clot) on emergency endoscopy (requiring endoscopic hemostasis).

\section{Statistical analysis}

Standard descriptive statistics, including means, medians and SDs were used to characterize the cohort. BUN was used as a continuous variable, while blood transfusion was used as a dicotomous variable (ie, yes or no).

Comparisons were made between those with and without severe nonvariceal UGIB, as well as between those exhibiting HRLs, using Wilcoxon's signed rank test. Multivariate analysis using logistic regression modelling (stepwise method) was performed to predict ICU admission, severe UGIB and HRLs, while adjusting for possible covariates (ie, SBP, American Society for Anesthesiologists score, rectal examination and nasogastric aspirate findings) (Table 2). The 95\% CIs are reported for ORs of the predictors included in the final model, as are $\mathrm{P}$ values with a
TABLE 3

Univariate analysis of blood urea nitrogen (BUN) as a predictor of severity* of upper gastrointestinal bleeding (UGIB) and the presence of high-risk endoscopic lesions

\begin{tabular}{lcc}
\hline Marker of UGIB & Mean BUN \pm SD, mmol/L & $\mathbf{P}^{\dagger}$ \\
\hline ICU admission & $14.7 \pm 10.4$ & 0.035 \\
No ICU admission & $12.0 \pm 8.0$ & \\
Blood transfusion & $14.1 \pm 10.6$ & 0.508 \\
No blood transfusion & $13.6 \pm 8.6$ & \\
High-risk lesion & $14.2 \pm 10.7$ & 0.605 \\
No high-risk lesion & $12.9 \pm 8.6$ &
\end{tabular}

*Severe bleeding was defined as bleeding that required blood transfusion or intensive care unit (ICU) admission; ${ }^{\dagger} P$ values are reported for ORs of the predictors included in the final model, with a significance threshold of $P<0.05$.

significance threshold of $\mathrm{P}<0.05$. All analyses were performed using SAS 9.1 (SAS Institute Inc, USA).

\section{RESULTS}

The RUGBE registry included 1869 patients, of which 239 were treated at the MUHC. Patients with known renal failure ( $\mathrm{n}=17)$, confounding conditions that could alter BUN level (ie, fever, trauma, infection, on steroids) $(n=8)$ and those with no recorded BUN or creatinine levels $(n=5)$ were excluded, leaving 209 patients for the analysis. (Figure 1).

The study population had a mean $( \pm \mathrm{SD})$ age of $67 \pm 18$ years, with a mean BUN level of $13.4 \pm 9.4 \mathrm{mmol} / \mathrm{L}$ (Table 1 ). Nearly one-half of the patients (98 patients, $45.1 \%$ ) required blood transfusions, and just over one-half (111 patients, 53.1\%) required an ICU admission for nonvariceal UGIB. Fortyfive patients $(21.5 \%)$ required neither ICU admission nor blood transfusion. HRLs were found in 78 patients (37.3\%).

Univariate analysis demonstrated an association between high BUN level and markers of severe nonvariceal UGIB (Table 3). The mean BUN level in the group of patients requiring ICU admission was higher than those not requiring ICU admission $(14.7 \pm 10.4 \mathrm{mmol} / \mathrm{L}$ versus $12.0 \pm 8.0 \mathrm{mmol} / \mathrm{L}$, respectively; $\mathrm{P}=0.035$ ). There was no significant association between BUN level and blood transfusion requirements $(\mathrm{P}=0.508)$. The BUN levels were no different between those with a HRL and those without a HRL $(14.2 \pm 10.7 \mathrm{mmol} / \mathrm{L}$ versus $12.9 \pm 8.6 \mathrm{mmol} / \mathrm{L}$, respectively; $\mathrm{P}=0.605$ ) (Table 3 ). Multivariate analysis demonstrated that, after adjustment for systolic blood pressure, BUN became a weak predictor of ICU admission for UGIB (OR 1.03, 95\% CI 1.00 to $1.06, \mathrm{P}=0.08$ ).

\section{DISCUSSION}

A relationship between azotemia and gastrointestinal bleeding has been the main focus of many studies in the past (20-23). Elevated BUN level in UGIB patients can be due to ingested blood protein, secondary to prerenal azotemia or renal failure. It has been shown that blood ingestion results in mild to moderate azotemia $(21,23)$. Cohn et al $(24)$ administered $180 \mathrm{~g}$ of protein as whole blood $(800 \mathrm{cc})$ and observed an increase in the BUN level of $25 \%$ to $35 \%$. In our study, renal failure as a cause of high BUN level has been excluded, such that the only sources of high BUN level (from a source other than bleeding - although the latter is much less likely) would be UGIB, volume contraction or ingestion of protein. Timing of the BUN test from the onset of bleeding and site of bleeding 
could be a confounding factor because ingested blood protein needs time for digestion, absorption and BUN production.

Urashima et al (25) found that severity of bleeding could be determined by the BUN to creatinine ratio and that a decrease in the BUN to creatinine ratio indicates a cessation of bleeding. In their study, a linear relationship was found between the change in hemoglobin and the BUN to creatinine ratio. However, the study was based on only 16 UGIB cases in a pediatric population. Other studies on BUN to creatinine ratio that include adult populations (14-16) were unable to correlate this ratio with severity of nonvariceal UGIB. In addition, cirrhotic patients were included in some of these studies.

Contrary to the previous belief of a strong association between high BUN level and severe UGIB, the present study found that the BUN level did not predict the need for blood transfusion ( $\mathrm{P}=0.508)$ (Table 3$)$. The high BUN level in the group of patients not requiring blood transfusion could be secondary to prerenal azotemia or volume contraction from nonsignificant blood loss in patients with borderline renal function or perfusion that is not reflected by an acute rise in creatinine levels. Another explanation for the lack of correlation between high BUN level and the need for blood transfusion, is the strict criterion for blood transfusion implemented at the MUHC. Interestingly, a modified Blatchford score with predictive value was recently proposed that excluded BUN level as a predictive marker of the severity of UGIB (12).

The present study also demonstrates that an elevated BUN level is a weak predictor of the need for ICU admission, especially when BUN level is adjusted for other covariates such as low SBP (OR 1.03, 95\% CI 1.00 to $1.06, \mathrm{P}=0.08$ ). This is partly due to colinearity between low blood pressure and high BUN levels. It is also possible that the high BUN level may have been taken into account by the physician when deciding to admit a patient to the ICU. Hence, the BUN level may not be a predictor of severity of nonvariceal UGIB but simply a factor that may have partly determined whether the patient was admitted to the ICU.

Endoscopic findings can guide the decision for discharge, hospital admission or admission to an ICU. Active bleeding (spurting or oozing) or a nonbleeding visible vessel seen on endoscopy have the highest potential for rebleeding, with rates of approximately $55 \%$ and $43 \%$, respectively (17). Predicting these findings, especially in patients without frank hematemesis, will help guide the clinician in deciding the need for an

\section{REFERENCES}

1. Dulai GS, Gralnek IM, Oei TT, et al. Utilization of health care resources for low-risk patients with acute, nonvariceal upper GI hemorrhage: An historical cohort study. Gastrointest Endosc 2002;55:321-7.

2. Rockall TA, Logan RF, Devlin HB, Northfield TC. Incidence of and mortality from acute upper gastrointestinal haemorrhage in the United Kingdom. Steering Committee and members of the National Audit of Acute Upper Gastrointestinal Haemorrhage. BMJ 1995;311:222-6.

3. Blatchford O, Davidson LA, Murray WR, Blatchford M, Pell J. Acute upper gastrointestinal haemorrhage in west of Scotland: Case ascertainment study. BMJ 1997;315:510-4.

4. Silverstein FE, Gilbert DA, Tedesco FJ, Buenger NK. The national ASGE survey on upper gastrointestinal bleeding. I. Study design and baseline data. Gastrointest Endosc 1981;27:73-9.

5. Longstreth GF. Epidemiology of hospitalization for acute upper gastrointestinal hemorrhage: A population-based study. Am J Gastroenterol 1995;90:206-10. urgent endoscopy, given the protective role of endoscopic therapy in patients with HRLs (8). Unfortunately, our study found that a high BUN level was not significantly associated with the subsequent finding of HRLs $(\mathrm{P}=0.605)$ (Table 3$)$. To our knowledge, this is the first study to examine the correlation between BUN level and HRLs. The lack of correlation between high BUN level and HRLs, however, is not surprising given that a strong association between high BUN level and parameters of severe nonvariceal UGIB was not found.

\section{CONCLUSIONS}

In patients with nonvariceal UGIB, an elevated BUN level at initial presentation is a weak predictor of severity of bleeding when also accounting for other factors such as low SBP. Also, an elevated BUN level was not helpful in identifying patients with HRLs.

Dr Alan N Barkun is a Research Scholar (Cherecheur National) funded by the Fonds de la Récherche en Santé du Quebec.

ACKNOWLEDGMENTS: The RUGBE initiative was a collaborative effort supported by the Canadian Association of Gastroenterology and an unrestricted grant from Altana Pharma Canada, a Nycomed company (formerly Byk Canada Inc). The RUGBE investigators' group includes Alan Barkun, Carlo Fallone and Gad Friedman, from the MUHC (Montreal General Hospital and Royal Victoria Hospital sites) and the Sir Mortimer B Davis - Jewish General Hospital, (Montreal, Quebec); Raymond Lahaie, Georges Ghattas and Judith Dorais, from the Centre hospitalier de l'Université de Montreal, les pavillons hôpitaux St-Luc, Notre Dame, et Hôtel-Dieu (Montreal); Naoki Chiba, from Guelph General Hospital (Guelph, Ontario), the University of Guelph (Guelph) and McMaster University (Hamilton, Ontario); David Armstrong and John Marshall, from McMaster University and Hamilton Health Sciences (Hamilton); Norman Marcon, from St Michael's Hospital (Toronto, Ontario); Jonathon Love, from the Queen Elizabeth II Health Sciences Centre (Halifax, Nova Scotia); Alan Cockeram, from the Saint John Regional Hospital (Saint John, New Brunswick); Franzjoseph Schweiger, from Moncton Hospital (Moncton, New Brunswick); Jamie Gregor and John McDonald, from London Health Sciences Centre (University Hospital and Victoria Campuses, London, Ontario); Rob Enns, from Saint Paul's Hospital (Vancouver, British Columbia); and Richard Fedorak, Bob Bailey and Connie Switzer, from the University of Alberta (Edmonton, Alberta), Royal Alexandra Hospital (Edmonton) and Grey Nuns Community Hospital (Edmonton).

6. Peura DA, Lanza FL, Gostout CJ, Foutch PG. The American College of Gastroenterology Bleeding Registry: Preliminary findings. Am J Gastroenterol 1997;92:924-8.

7. Boonpongmanee S, Fleischer DE, Pezzullo JC, et al. The frequency of peptic ulcer as a cause of upper-GI bleeding is exaggerated. Gastrointest Endosc 2004;59:788-94.

8. Barkun A, Sabbah S, Enns R, et al; RUGBE Investigators. The Canadian Registry on Nonvariceal Upper Gastrointestinal Bleeding and Endoscopy (RUGBE): Endoscopic hemostasis and proton pump inhibition are associated with improved outcomes in a real-life setting. Am J Gastroenterol 2004;99:1238-46.

9. Wiesen AR, Hospenthal DR, Byrd JC, Glass KL, Howard RS, Diehl LF. Equilibration of hemoglobin concentration after transfusion in medical inpatients not actively bleeding. Ann Intern Med 1994;121:278-80.

10. Elizalde JI, Clemente J, Marin JL, et al. Early changes in hemoglobin and hematocrit levels after packed red cell transfusion in patients with acute anemia. Transfusion 1997;37:573-6. 
11. Das A, Wong RC. Prediction of outcome of acute GI hemorrhage: A review of risk scores and predictive models. Gastrointest Endosc 2004;60:85-93.

12. Blatchford O, Murray WR, Blatchford M. A risk score to predict need for treatment for upper-gastrointestinal haemorrhage. Lancet 2000;356:1318-21.

13. Rockey DC. Gastrointestinal bleeding. In: Feldman M, Friedman LS, Sleisenger MH, eds. Sleisenger \& Fordtran's Gastrointestinal and Liver Disease, 7th edn. Philadelphia: Saunders, 2002:211-48.

14. Snook JA, Holdstock GE, Bamforth J. Value of a simple biochemical ratio in distinguishing upper and lower sites of gastrointestinal haemorrhage. Lancet 1986;1:1064-5.

15. Ernst AA, Haynes ML, Nick TG, Weiss SJ. Usefulness of the blood urea nitrogen/creatinine ratio in gastrointestinal bleeding. Am J Emerg Med 1999;17:70-2.

16. Chalasani N, Clark WS, Wilcox CM. Blood urea nitrogen to creatinine concentration in gastrointestinal bleeding: A reappraisal. Am J Gastroenterol 1997;92:1796-9.

17. Laine L, Peterson WL. Bleeding peptic ulcer. N Engl J Med 1994;331:717-27.

18. Barkun A, Bardou M, Marshal JK; Nonvariceal Upper GI Bleeding Consensus Conference Group. Consensus recommendations for managing patients with nonvariceal upper gastrointestinal bleeding. Ann Intern Med 2003;139:843-57.

19. Bensoussan K, Fallone CA, Barkun AN, Martel M; RUGBE Investigators. A sampling of Canadian practice in managing nonvariceal upper gastrointestinal bleeding before recent guideline publication: Is there room for improvement? Can J Gastroenterol 2005;19:487-95

20. Black DAK. Critical review. Azotemia in gastro-duodenal hemorrhage. Q J Med 1942;11:77-104.

21. Schiff L, Stevens RJ, Goodman S, et al. Observations on the oral administration of citrated blood in man. Am J Dig Dis 1939;6:597-601.

22. Johnson JB. The pathogenesis of azotemia in hemorrhage from upper gastrointestinal tract. J Clin Invest 1941;20:161-8.

23. Greenblatt IJ, Cohn TD. Azotemia in gastrointestinal bleeding. The ingestion of shed blood in humans. Am J Med Sci 1946;211:565-70.

24. Cohn TD, Lane M, Zuckerman S, et al. Induced azotemia in humans following massive protein and blood ingestion and mechanism of azotemia in gastrointestinal hemorrhage. Am J Med Sci 1956;231:394-401.

25. Urashima M, Toyoda S, Nakano T, et al. BUN/Cr ratio as an index of gastrointestinal bleeding mass in children. J Pediatr Gastroenterol Nutr 1992;15:89-92. 


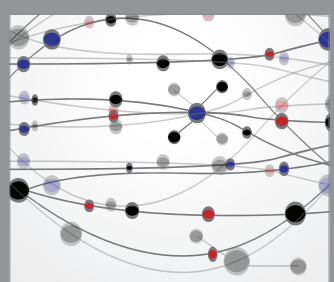

The Scientific World Journal
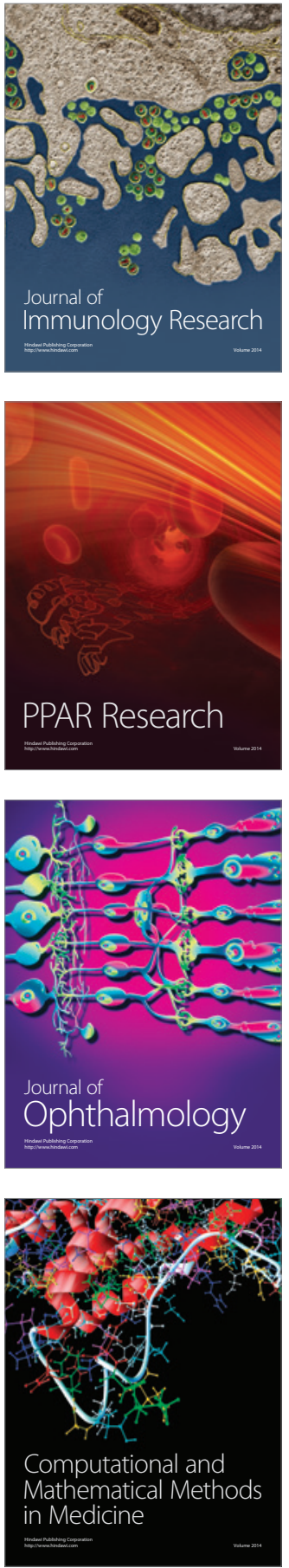

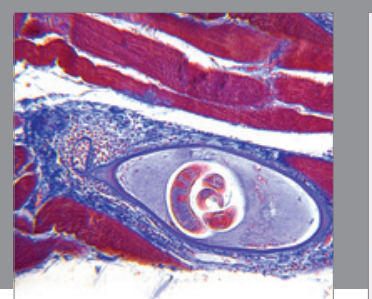

Gastroenterology Research and Practice

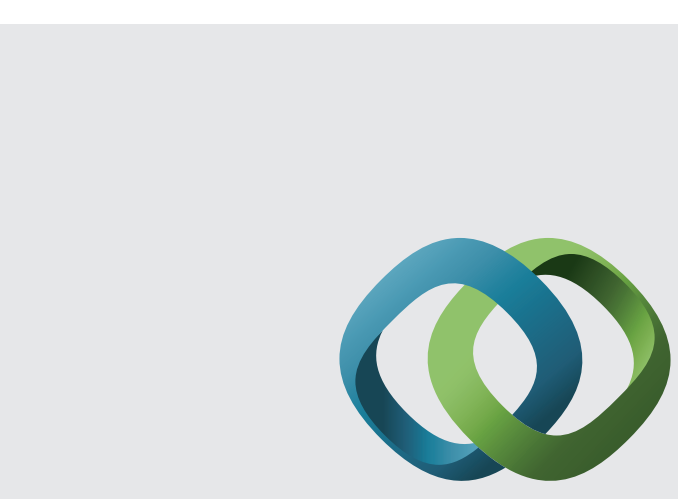

\section{Hindawi}

Submit your manuscripts at

http://www.hindawi.com
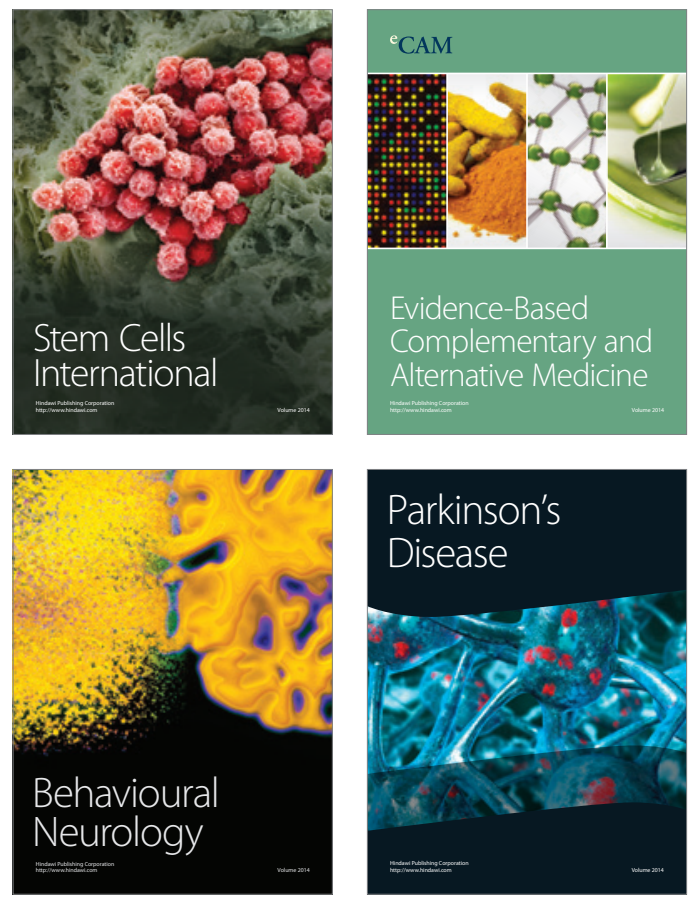
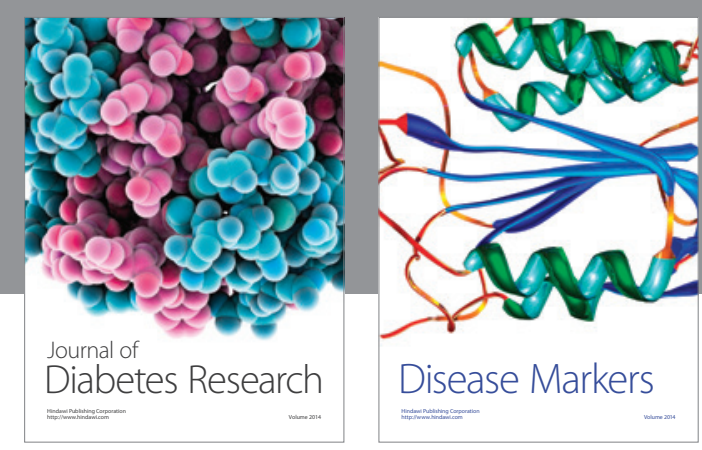

Disease Markers
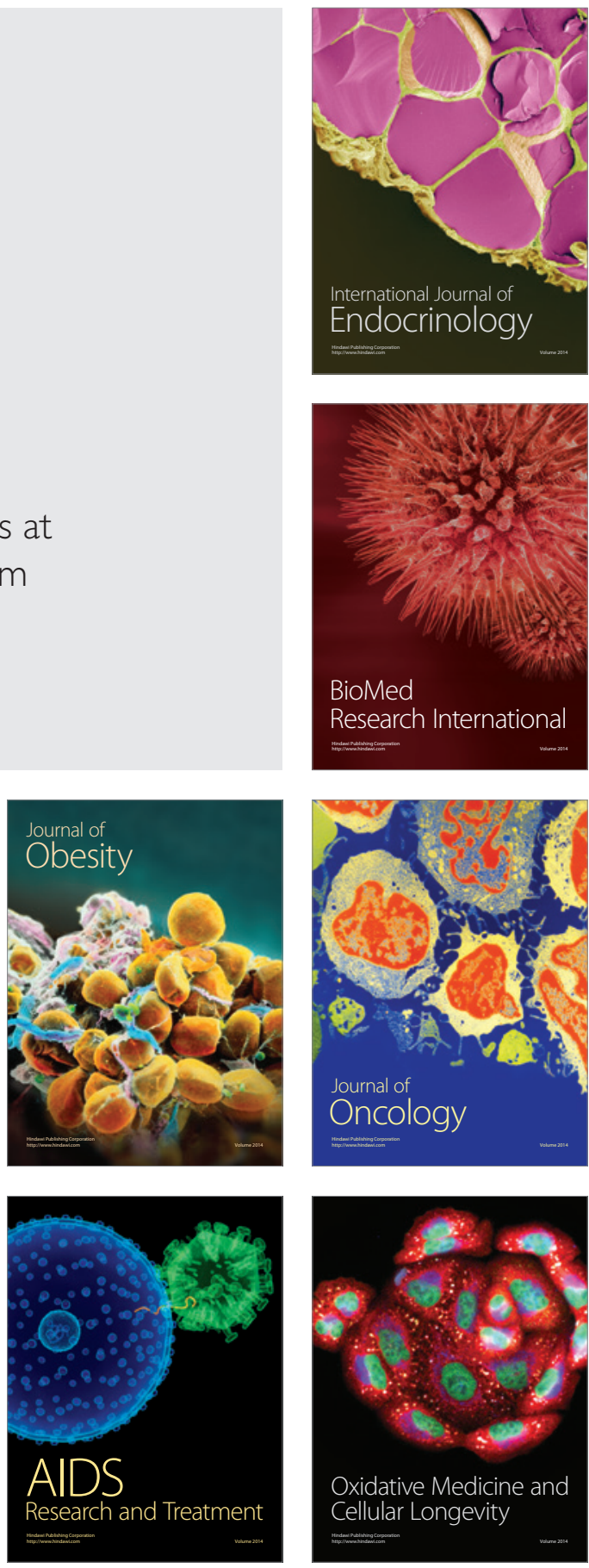